\title{
Numerical investigation of influences of liquid types on flow distribution and temperature distribution in disc type ON cooled transformers
}

DOI:

10.1109/ICDL.2017.8124677

\section{Document Version}

Accepted author manuscript

Link to publication record in Manchester Research Explorer

Citation for published version (APA):

Zhang, X., Wang, Z., Liu, Q., Negro, M., Gyore, A., \& Smith, P. W. R. (2017). Numerical investigation of influences of liquid types on flow distribution and temperature distribution in disc type ON cooled transformers. In 2017 IEEE 19th International Conference on Dielectric Liquids (ICDL) (pp. 1-4) https://doi.org/10.1109/ICDL.2017.8124677

Published in:

2017 IEEE 19th International Conference on Dielectric Liquids (ICDL)

\section{Citing this paper}

Please note that where the full-text provided on Manchester Research Explorer is the Author Accepted Manuscript or Proof version this may differ from the final Published version. If citing, it is advised that you check and use the publisher's definitive version.

\section{General rights}

Copyright and moral rights for the publications made accessible in the Research Explorer are retained by the authors and/or other copyright owners and it is a condition of accessing publications that users recognise and abide by the legal requirements associated with these rights.

\section{Takedown policy}

If you believe that this document breaches copyright please refer to the University of Manchester's Takedown Procedures [http://man.ac.uk/04Y6Bo] or contact uml.scholarlycommunications@manchester.ac.uk providing relevant details, so we can investigate your claim.

\section{OPEN ACCESS}




\section{Numerical Investigation of Influences of Liquid Types on Flow Distribution and Temperature Distribution in Disc Type ON Cooled Transformers}

\author{
Xiang Zhang ${ }^{1}$, Zhongdong Wang ${ }^{1}$, Qiang Liu ${ }^{1}$ \\ ${ }^{1}$ School of Electrical \& Electronic Engineering \\ The University of Manchester \\ Manchester, UK \\ zhongdong.wang@manchester.ac.uk
}

\begin{abstract}
In this paper, dimensional analysis is adopted to study fluid flow distribution and temperature distribution in disc-type ON (oil natural) cooled transformer windings. Theoretical analysis on the thermal driving force and the pressure drop in the liquid circulation loop is also performed to determine the total liquid flow rate in the transformer. The thermal performance of three different liquids, a hydrocarbon mineral oil, a hydrocarbon gas-to-liquid (GTL) oil and a synthetic ester are investigated using computational fluid dynamics (CFD) simulations, based on the understanding from dimensional analysis and the flow rates determined from the theoretical analysis. It is found in the investigated conditions that the hydrocarbon mineral and GTL oil share similar thermal performance; the synthetic ester has a lower total flow rate due to its higher viscosity and therefore requires additional effort to improve the thermal performance.
\end{abstract}

Keywords-CFD; dimensional alanalysis; disc-type winding; flow distribution; hot-spot temperature;hot-spot factor; ON transformer; ester; mineral oil; GTL oil

\section{INTRODUCTION}

Power transformers connect power systems of different voltage levels. The reliability of the transformer is of great importance to the reliability and safety of the power system. Apart from premature failure due to faults, transformer life expectancy is mainly dictated by the thermal ageing process of the insulation cellulose $[1,2]$. The highest temperature in the winding, usually referred to as the hot-spot temperature, is of great interest to the transformer thermal designer and operator because it causes the severest thermal degradation.

Generally, the cooling of the windings of power transformers relies on the circulation of the dielectric coolant fluid between the radiator and the winding. The liquid flow distribution in conjunction with power loss distribution determines the temperature distribution. The liquid flow and the heat transfer processes in the winding, are mainly investigated by using thermal-hydraulic network models and models that incorporate computational fluid dynamics (CFD). For oil directed (OD) cooling modes, liquid flow and heat transfer are weakly coupled. Therefore, the hydraulic system and the thermal system can be investigated separately [3-5]. For oil forced/natural (OF/ON) cooling modes, liquid flow and heat transfer are strongly coupled and therefore buoyancy force and hot-streak dynamics play vital roles in determining the fluid flow and temperature distribution in the winding [6-8].

Other than traditional hydrocarbon mineral oil, alternative liquids like synthetic esters, natural esters and hydrocarbon gas-to-liquid (GTL) oils are increasingly being used as dielectric coolant for power transformers due to their

\author{
Massimo Negro ${ }^{2}$, Attila Gyore ${ }^{3}$, Peter W.R. Smith ${ }^{4}$ \\ ${ }^{2}$ Weidmann Electrical Technology AG, Chiasso, \\ Switzerland \\ ${ }^{3} \mathrm{M} \&$ I Materials, Manchester, UK \\ ${ }^{4}$ Shell Global Solutions, Manchester, UK
}

properties and performance, and potential for reduced fire and environmental risks. The influences of different liquids on OD transformer flow and temperature distributions are shown in [9]. In this paper, fluid flow and temperature distributions in disc-type ON transformer windings are investigated theoretically, followed by numerical investigation of the influences of different liquids upon the fluid flow distribution and the temperature distribution.

\section{WINDING GEOMETRY UNDER INVESTIGATION}

The winding under investigation is a $\mathrm{LV}$ winding of a 66 MVA $225 / 26.4 \mathrm{kV}$ ONAN/ONAF transmission transformer [10]. This LV winding consists of 4 passes with pass 1 at the bottom being an anomaly, as shown in Fig. 1. There are 2 parts in pass 1 . Part 1 is not representative of an $\mathrm{ON}$ transformer winding pass with 2 discs and three horizontal ducts. Part 2 is a typical ON winding pass and it is repeated to become the other 3 following passes with inlet alternating between the inner and outer vertical ducts to form a zigzag flow pattern. Since the geometry of the last 3 passes repeats part 2 of pass 1 , the geometry of the whole winding is not illustrated in Fig. 1.

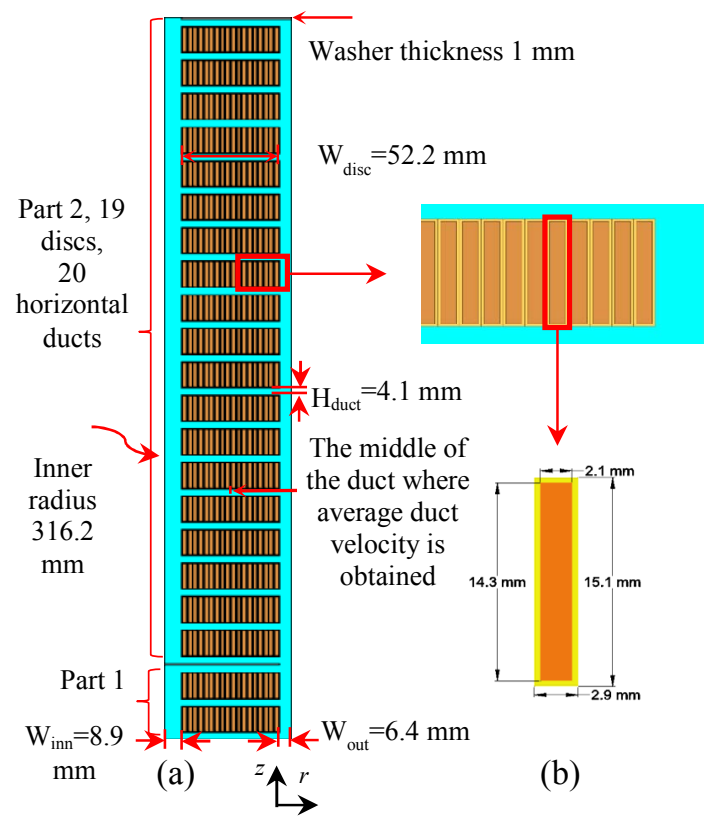

Fig. 1. Axisymmetric 2D geometry. (a) Winding geometry of pass 1 at the bottom of the LV winding. (b) Geometric details of one strand. 


\section{DIMENSIONAL ANALYSIS}

Heat transfer in the winding involves conduction in the solid domain (copper and paper insulation) and convection in the fluid domain. The conduction is governed by Fourier's law of conduction. The convection, which is the challenging part, is governed by three conservation laws, i.e. the conservations of mass, momentum and energy.

\section{A. Boussinesq Approximation}

According to the Boussinesq approximation all fluid properties are assumed constant except for density in the buoyancy force term. In cylindrical coordinates, the conservation equations of mass, momentum and energy for axisymmetric 2D flow can be expressed by (1), (2) and (3), respectively.

$$
\begin{aligned}
& \frac{1}{r} \frac{\partial\left(\mathrm{ru}_{r}\right)}{\partial r}+\frac{\partial u_{z}}{\partial z}=0 \\
& \left\{\begin{array}{l}
\mathrm{u}_{r} \frac{\partial u_{r}}{\partial r}+\mathrm{u}_{z} \frac{\partial u_{r}}{\partial z}=-\frac{1}{\rho} \frac{\partial p}{\partial r}+v\left(\frac{\partial}{\partial r}\left(\frac{1}{r} \frac{\partial\left(\mathrm{ru}_{r}\right)}{\partial r}\right)+\frac{\partial^{2} u_{r}}{\partial z^{2}}\right) \\
\mathrm{u}_{r} \frac{\partial u_{z}}{\partial r}+\mathrm{u}_{z} \frac{\partial u_{z}}{\partial z}=g \beta\left(T-T_{t o}\right)+v\left(\frac{1}{r} \frac{\partial}{\partial r}\left(\mathrm{r} \frac{\partial u_{z}}{\partial r}\right)+\frac{\partial^{2} u_{z}}{\partial z^{2}}\right)
\end{array}\right. \\
& u_{r} \frac{\partial T}{\partial r}+u_{z} \frac{\partial T}{\partial z}=\frac{k}{\rho c_{p}}\left(\frac{1}{r} \frac{\partial}{\partial r}\left(\mathrm{r} \frac{\partial T}{\partial r}\right)+\frac{\partial^{2} T}{\partial z^{2}}\right)
\end{aligned}
$$

where $r(\mathrm{~m})$ is denoted for the radial coordinate, $u_{r}(\mathrm{~m} / \mathrm{s})$ for velocity radial component, $z(\mathrm{~m})$ for axial coordinate, $u_{z}$ $(\mathrm{m} / \mathrm{s})$ for velocity axial component, $\rho\left(\mathrm{kg} / \mathrm{m}^{3}\right)$ for liquid density, $p(\mathrm{~Pa})$ for static pressure, $v\left(\mathrm{~m}^{2} / \mathrm{s}\right)$ for kinematic viscosity, $g\left(\mathrm{~m} / \mathrm{s}^{2}\right)$ for gravitational acceleration, $\beta(1 / \mathrm{K})$ for volumetric thermal expansion coefficient, $T(\mathrm{~K})$ for liquid temperature, $T_{t o}(\mathrm{~K})$ for liquid temperature at the top of the winding, $k(\mathrm{~W} /(\mathrm{m} \cdot \mathrm{K}))$ for liquid thermal conductivity, $c_{p}$ $(\mathrm{J} /(\mathrm{kg} \cdot \mathrm{K}))$ for liquid specific heat

It is worth mentioning that the viscous dissipation term in the energy equation is neglected due to the small flow rate in transformer windings.

\section{B. Dimensionless Forms}

To transfer the governing equations to their dimensionless forms, the dimensionless independent variables are defined as:

$$
\begin{aligned}
& r^{*}=\frac{r}{D_{h}} \quad \text { and } \quad z^{*}=\frac{z}{D_{h}} \\
& u_{r}^{*}=\frac{u_{r}}{u_{m}} \quad \text { and } \quad u_{z}^{*}=\frac{u_{z}}{u_{m}} \\
& p^{*}=\frac{p}{\rho u_{m}^{2}} \quad \text { and } \quad T^{*}=\frac{T-T_{t o}}{T_{a w}-\left(\mathrm{T}_{t o}+\mathrm{T}_{b o}\right) / 2}=\frac{T-T_{t o}}{g_{a v e}}
\end{aligned}
$$

where $D_{h}(\mathrm{~m})$ is denoted for hydraulic diameter, defined as twice the inner vertical duct width $\left(w_{i n n}\right), u_{m}(\mathrm{~m} / \mathrm{s})$ for average liquid velocity at the inner vertical duct inlet, $T_{a w}$ $(\mathrm{K})$ for average winding temperature, $T_{b o}(\mathrm{~K})$ for winding bottom liquid temperature, $g_{\text {ave }}(\mathrm{K})$ for the average temperature gradient between the winding and the average liquid temperature taken as the average of winding top and bottom liquid temperatures.

Substituting (4), (5) and (6) into the governing equations and noticing that the reference parameters $\left(D_{h}, T_{a w}, T_{t o}, T_{b o}\right.$, $u_{m}$ ) are not functions of the coordinates, we have the dimensionless governing equations:

$$
\begin{aligned}
& \frac{1}{r^{*}} \frac{\partial\left(\mathrm{r}^{*} \mathrm{u}_{r}^{*}\right)}{\partial r^{*}}+\frac{\partial u_{z}^{*}}{\partial z^{*}}=0 \\
& \left\{\begin{array}{l}
\mathrm{u}_{r}^{*} \frac{\partial u_{r}^{*}}{\partial r^{*}}+\mathrm{u}_{z}^{*} \frac{\partial u_{r}^{*}}{\partial z^{*}}=-\frac{\partial p^{*}}{\partial r^{*}}+\frac{1}{\operatorname{Re}}\left(\frac{\partial}{\partial r^{*}}\left(\frac{1}{r^{*}} \frac{\partial\left(\mathrm{r}^{*} \mathrm{u}_{r}^{*}\right)}{\partial r^{*}}\right)+\frac{\partial^{2} u_{r}^{*}}{\partial z^{* 2}}\right) \\
\mathrm{u}_{r}^{*} \frac{\partial u_{z}^{*}}{\partial r^{*}}+\mathrm{u}_{z}^{*} \frac{\partial u_{z}^{*}}{\partial z^{*}}=\frac{G r}{\operatorname{Re}^{2}} T^{*}+\frac{1}{\operatorname{Re}}\left(\frac{1}{r^{*}} \frac{\partial}{\partial r^{*}}\left(\mathrm{r}^{*} \frac{\partial u_{z}^{*}}{\partial r^{*}}\right)+\frac{\partial^{2} u_{z}^{*}}{\partial z^{2}}\right)
\end{array}\right. \\
& u_{r}^{*} \frac{\partial T^{*}}{\partial r^{*}}+u_{z}^{*} \frac{\partial T^{*}}{\partial z^{*}}=\frac{1}{\operatorname{Re} \cdot \operatorname{Pr}}\left(\frac{1}{r^{*}} \frac{\partial}{\partial r^{*}}\left(\mathrm{r}^{*} \frac{\partial T^{*}}{\partial r^{*}}\right)+\frac{\partial^{2} T^{*}}{\partial z^{* 2}}\right)
\end{aligned}
$$

where the definitions of $\operatorname{Re}, \operatorname{Pr}$ and $\mathrm{Gr} / \mathrm{Re}^{2}$ are shown below:

$$
\begin{aligned}
& \operatorname{Re}=\frac{u_{m} D_{h}}{v} \\
& \operatorname{Pr}=\frac{\mu c_{p}}{k} \\
& \frac{G r}{\operatorname{Re}^{2}}=\frac{g \beta\left(T_{a w}-\left(T_{t o}+T_{b o}\right) / 2\right) D_{h}}{u_{m}^{2}}
\end{aligned}
$$

where $\mu(\mathrm{Pa} \cdot \mathrm{s})$ stands for liquid dynamic viscosity.

\section{Flow and temperature distribution in the fluid domain}

For a fixed winding geometry with a fixed power loss distribution in dimensionless senses, both liquid flow distribution and temperature distribution are determined by the coefficients, $\mathrm{Re}, \mathrm{Gr} / \mathrm{Re}^{2}$ and $\mathrm{Pr}$ as shown in the dimensionless governing equations (7)-(9). Pr plays the same role as $\mathrm{Re}$ in (9). Re in conjunction with $\mathrm{Gr} / \mathrm{Re}^{2}$ determines liquid flow distribution in (8). For ON cooling modes, flow and temperature are strongly coupled. Therefore, $\mathrm{Re}$ is more influential than $\mathrm{Pr}$ in determining flow and temperature distribution. $\mathrm{Gr} / \mathrm{Re}^{2}$ is related to buoyancy force which is the main driving force of the flow. In conclusion, liquid flow distribution and temperature distribution are mainly controlled by $\mathrm{Re}, \operatorname{Pr}$ and $\mathrm{Gr} / \mathrm{Re}^{2}$. Following the same argument as presented in [11], we can conclude that the hot-spot factor for $\mathrm{ON}$ cooling modes are mainly controlled by $\mathrm{Re}, \operatorname{Pr}$ and $\mathrm{Gr} / \mathrm{Re}^{2}$.

\section{DEtermination of TOtal LiQuid Flow RATE}

For ON cooling modes, total liquid flow rate in the winding has a significant influence on the liquid flow distribution, and the temperature distribution. The total liquid flow rate is determined by the thermal driving force $\left(p_{T}\right)$ and the pressure drop $\left(p_{D}\right)$ over the whole circulation loop. A schematic illustration of the loop is shown in Fig. 2.

\section{A. Thermal Driving Force}

The thermal driving force can be expressed as:

$$
p_{T}=\oint \rho \cdot \vec{g} d \vec{l}
$$

Under the assumptions that heat transfer occurs only in the winding and the radiator, and temperatures rise linearly with elevation in the winding and the radiator, the thermal driving force in (13) can be approximated to be:

$$
p_{T}=\rho_{0} \cdot g \cdot \beta \cdot \Delta T \cdot \Delta H
$$

where $\rho_{0}\left(\mathrm{~kg} / \mathrm{m}^{3}\right)$ is a reference density at $20{ }^{\circ} \mathrm{C}, \Delta T(\mathrm{~K})$ is the liquid temperature gradient between the top and bottom 
of the winding, $\Delta H(\mathrm{~m})$ is height difference of the central points of the radiator and the winding.

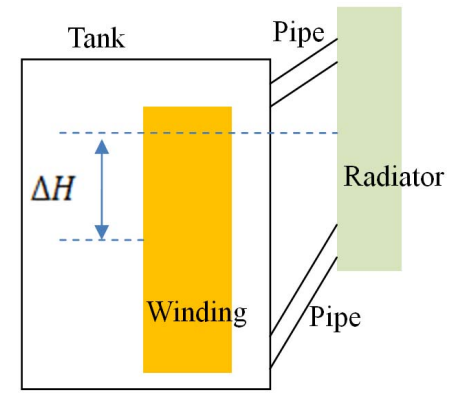

Fig. 2. Schematic illustration of the liquid circulation loop.

\section{B. Pressure Drop in the Loop}

The pressure drop in the loop is determined by the geometry, liquid properties and liquid flow rate. It is verified experimentally that for ON cooling modes, the so called minor pressure drops related to the change of flow direction is negligible, compared to the major pressure drop due to friction [7]. Therefore, the pressure drop over the loop can be expressed as:

$p_{D}=\frac{C}{\operatorname{Re}} \frac{L^{\prime}}{H^{\prime}} \frac{\rho u_{m}^{2}}{2}$

where $\mathrm{C}$ is a constant, $\mathrm{L}^{\prime}(\mathrm{m})$ and $\mathrm{H}^{\prime}(\mathrm{m})$ are the equivalent length and the equivalent diameter of the circulation loop.

\section{Determination of Total Flow Rate}

Applying energy conservation to the total liquid flow through the winding or the radiator, in steady state we have:

$\Delta \mathrm{T}=\frac{P}{\dot{m} c_{p}}=\frac{P}{A u_{m} \rho c_{p}}$

where $\mathrm{P}(\mathrm{W})$ is the total power loss in the winding or radiator, $\mathrm{A}$ is the cross sectional area of the winding inlet.

Combining (14), (15) and (16), we have:

$u_{m}^{2}=\frac{2 \rho_{0} g \beta H^{\prime 2}}{\mu C L^{\prime} A \rho c_{p}} \Delta H \cdot P$

Notice that for a given liquid and a given winding geometry $\rho_{0}, g, \beta, H^{\prime}, L^{\prime}, \mu, C, A, \rho, c_{p}$ can all be treated as constant. Therefore the total liquid flow rate characterized by the winding inlet velocity $u_{m}$ is proportional to the square root of the total power loss in the winding, and the square root of the central point height difference between the radiator and the winding. These square root relationships between $u_{m}$ and $P$ and $\Delta H$ are obtained experimentally in [7].

\section{INFLUENCES OF LIQUID TYPES}

For a fixed winding geometry (fixed geometrical boundary conditions and fixed $\Delta H$ ) with a fixed power loss distribution (fixed $P$ ), the total liquid flow rate is determined by the properties of the liquid as shown in (17). In (17), liquid-type related properties are $\rho_{o}, \mu, \rho$ and $c_{p}$. Three types of liquid are investigated in this paper. They are a traditional hydrocarbon mineral oil, a hydrocarbon gas-to-liquid (GTL) oil and a synthetic ester. The properties of these three liquids are obtained from least-square curve fittings of the results provided by the manufacturers.

$$
\left\{\begin{array}{l}
\rho_{1}=-0.6568 \times T+1064\left[\mathrm{~kg} / \mathrm{m}^{3}\right] \\
\rho_{2}=-0.6455 \times T+995.5\left[\mathrm{~kg} / \mathrm{m}^{3}\right] \\
\rho_{3}=-0.7327 \times T+1185\left[\mathrm{~kg} / \mathrm{m}^{3}\right] \\
\mu_{1}=7.863 \times 10^{-5} \times \exp (632.0 /(T-176.0))[\mathrm{Pa} \cdot \mathrm{s}] \\
\mu_{2}=6.133 \times 10^{-5} \times \exp (749.8 /(T-157.4))[\mathrm{Pa} \cdot \mathrm{s}] \\
\mu_{3}=6.239 \times 10^{-5} \times \exp (914.1 /(T-162.4))[\mathrm{Pa} \cdot \mathrm{s}] \\
c_{p 1}=3.950 \times T+560[\mathrm{~J} /(\mathrm{kg} \cdot \mathrm{K})] \\
c_{p 2}=4.449 \times T+871.7[\mathrm{~J} /(\mathrm{kg} \cdot \mathrm{K})] \\
c_{p 3}=2.069 \times T+1287[\mathrm{~J} /(\mathrm{kg} \cdot \mathrm{K})] \\
\beta_{1}=7.778 \times 10^{-4}[1 / \mathrm{K}] \\
\beta_{2}=8.273 \times 10^{-4}[1 / \mathrm{K}] \\
\beta_{3}=7.790 \times 10^{-4}[1 / \mathrm{K}]
\end{array}\right.
$$

where the subscript 1 is for the mineral oil, 2 for the GTL, 3 for the synthetic ester, $T$ for temperature in Kelvin.

When we choose the flow rate of mineral oil as a unit, and liquid temperature as $70{ }^{\circ} \mathrm{C}$ to determine the properties ( $\rho_{0}$ is determined at $20^{\circ} \mathrm{C}$ ), according to (17), the volumetric flow rate for the mineral oil, the GTL oil and the synthetic ester is 1: 0.919: 0.581 .

Computations have been performed by using commercial finite element method based software COMSOL Multiphysics in laminar model. To compare the thermal performance of the three liquids, the winding inlet temperature is fixed to be $46.7^{\circ} \mathrm{C}$ and the power loss of each disc is set to be $420 \mathrm{~W}$, corresponding to a current density of $4 \mathrm{~A} / \mathrm{mm}^{2}$ at $85{ }^{\circ} \mathrm{C}$ copper resistance. The flow rate of the mineral oil is the benchmark which corresponds to a winding inlet velocity of $0.053 \mathrm{~m} / \mathrm{s}$. The inlet velocity of the GTL oil and the synthetic ester is therefore $0.049 \mathrm{~m} / \mathrm{s}$ and $0.031 \mathrm{~m} / \mathrm{s}$, respectively.

The average liquid velocity in the middle of each horizontal cooling duct and the maximum temperature of each disc are shown in Fig. 3 and Fig. 4 respectively. Since part 1 of pass 1 is not representative of an ON transformer winding pass, the flow and temperature results in this part is not included in this paper. The comparisons of some lumped parameters and hot-spot temperature for these three liquids are shown in Table 1.

It can be seen from Fig. 3 and Fig. 4 that both hydrocarbons, the mineral oil and the GTL oil, share similar flow and temperature distribution because they have similar Re, $\operatorname{Pr}$ and $\mathrm{Gr} / \mathrm{Re}^{2}$ as shown in Table 1. Although the mineral oil has a slightly higher total flow rate than the GTL oil, the temperature of the GTL oil is slightly lower than the mineral oil due to its higher thermal conductivity and higher specific heat (which arise from its lower density). The synthetic ester has a much lower flow rate than the other two liquids and therefore has lower velocities in most of the horizontal ducts and higher disc temperatures. The flow distribution and temperature distribution of the synthetic ester are very different from those of the mineral oil and the 
GTL oil because they have quite different Re, Pr and $\mathrm{Gr} / \mathrm{Re}^{2}$ as shown in Table 1. For the synthetic ester, the liquid at the top part of pass 4 is almost in stagnation, causing overheating at the top of the winding. The distorted temperature distribution of the synthetic ester results in a larger hot-spot factor than the other two liquids. To improve the thermal performance of the synthetic ester, a higher total liquid flow rate is needed. According to (17), a feasible way to do this would be to increase the height difference between the centre line of the radiator and the centre line of the winding, $\Delta \mathrm{H}$.

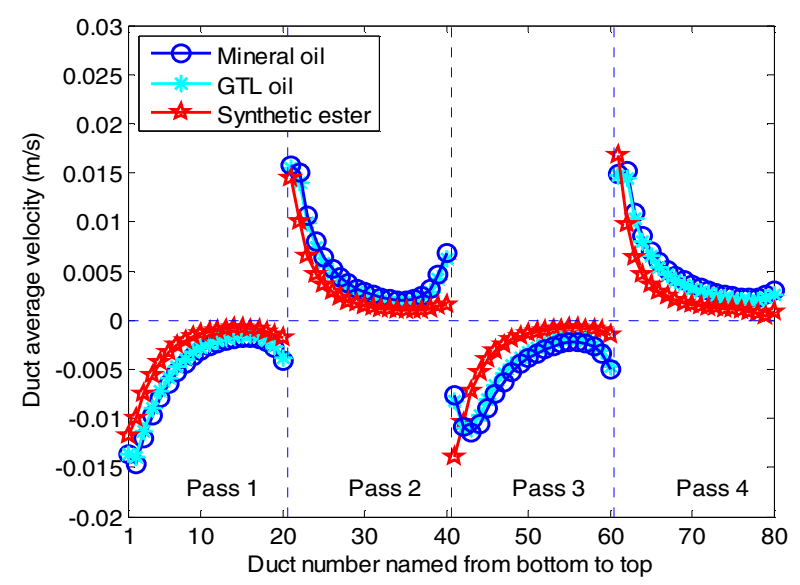

Fig. 3. Average liquid velocity in each horizontal cooling duct. Flow from outer vertical duct to inner vertical duct is set to be negative and vice versa.

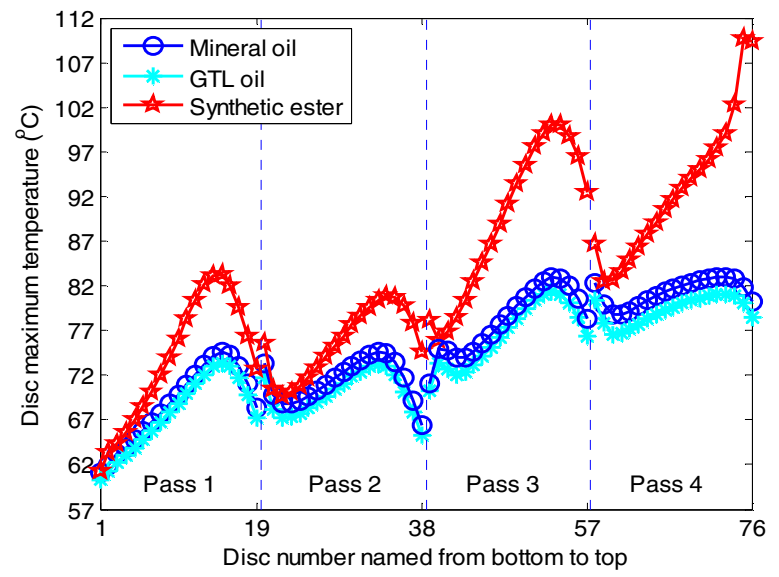

Fig. 4. Maximum temperature of each disc.

Table 1. Comparisons of lumped parameters

\begin{tabular}{c|ccccccc}
\hline \hline & $\begin{array}{c}\mathrm{T}_{\mathrm{aw}} \\
\left({ }^{\circ} \mathrm{C}\right)\end{array}$ & $\begin{array}{c}\mathrm{T}_{\text {to }} \\
\left({ }^{\circ} \mathrm{C}\right)\end{array}$ & $\begin{array}{c}\mathrm{T}_{\mathrm{hs}} \\
\left({ }^{\circ} \mathrm{C}\right)\end{array}$ & $\mathrm{Re}$ & $\mathrm{Pr}$ & $\mathrm{Gr} / \mathrm{Re}^{2}$ & $\mathrm{H}$ \\
\hline $\begin{array}{c}\text { Mineral } \\
\text { oil }\end{array}$ & 70.4 & 67.4 & 83.0 & 169 & 68 & 0.65 & 1.17 \\
$\begin{array}{c}\text { GTL oil } \\
\text { Synthetic } \\
\text { ester }\end{array}$ & 69.1 & 66.1 & 81.4 & 143 & 80 & 0.72 & 1.20 \\
\hline \hline
\end{tabular}

where $T_{a w}$ refers to average winding temperature, $T_{\text {to }}$ to top oil temperature, $\mathrm{T}_{\text {hs }}$ to hot-spot temperature, $H$ to hot-spot factor. Re, $\mathrm{Pr}$ and $\mathrm{Gr} / \mathrm{Re}^{2}$ are calculated based on oil properties at the average of winding top oil and winding bottom oil temperatures.

\section{CONCLUSION}

Dimensional analysis on fluid flow and heat transfer in the winding has been performed for $\mathrm{ON}$ transformers. It is found that for a fixed winding geometry and a fixed power loss distribution in dimensionless senses the flow distribution and temperature distribution is governed by $\mathrm{Re}$, Pr and $\mathrm{Gr} / \mathrm{Re}^{2}$.

Theoretical analysis of the thermal driving force and the pressure drop in the liquid circulation loop, shows that the total volumetric flow rate is proportional to the square root of the power loss in the winding, and the square root of the height difference between the centre line of the radiator and the centre line of the winding, $\Delta \mathrm{H}$.

For different liquids, the ratios of total liquid flow rate are determined. CFD simulations of typical cases are performed. It is found that the hydrocarbon mineral oil gives similar thermal performance to the GTL oil in this evaluation. The synthetic ester on the other hand has quite different flow and temperature distribution due to the significant differences in $\mathrm{Re}, \mathrm{Pr}$ and $\mathrm{Gr} / \mathrm{Re}^{2}$. The low liquid flow rate of the synthetic ester can cause local overheating in the winding. A feasible way to improve the thermal performance of the synthetic ester would be to increase $\Delta \mathrm{H}$.

\section{Acknowledgment}

The authors would like to express their gratitude to M\&I Materials, National Grid, Scottish Power, Shell, TJ $\mid \mathrm{H} 2 \mathrm{~b}$ Analytical Services, UK Power Networks and Weidmann Electrical Technology AG for their financial and technical contributions to the Transformer Research Consortium at The University of Manchester.

References

[1] IEC, "Loading Guide for Oil-immersed Power Transformers," IEC standard 60076-7, 2005.

[2] IEEE, "IEEE Guide for Loading Mineral-Oil-Immersed Transformers and Step-Voltage Regulators," IEEE standard C57.91, 2011.

[3] X. Zhang, Z. D. Wang, and Q. Liu, "Prediction of Pressure drop and flow distribution in disc type transformer windings under an OD cooling mode," IEEE Transactions on Power Delivery, vol. DOI (identifier) 10.1109/TPWRD.2016.2557490, In press, 2016. X. Zhang, Z. D. Wang, Q. Liu et al., "Investigation of Convective Heat Transfer Efficiency in the Horizontal Cooling Duct of a Disc Type Transformer Winding," in 19th International Symposium on High Voltage Engineering (ISH), Paper ID 280, Pilsen, Czech Republic, 2015.

M. Nakadate, K. Toda, K. Sato et al., "Gas Cooling Performance in Disc Winding of Large-capacity Gas-insulated Transformer," IEEE Transactions on Power Delivery, vol. 11, no. 2, pp. 903908, 1996.

[6] A. Skillen, A. Revell, H. Iacovides et al., "Numerical Prediction of Local Hot-spot Phenomena in Transformer Windings," Applied Thermal Engineering, vol. 36, pp. 96-105, 2012.

[7] M. Yamaguchi, T. Kumasaka, Y. Inui et al., "The Flow Rate in a Self-cooled Transformer," IEEE Transactions on Power Apparatus and Systems, no. 3, pp. 956-963, 1981

[8] F. Torriano, M. Chaaban, and P. Picher, "Numerical Study of Parameters Affecting the Temperature Distribution in a Disctype Transformer Winding," Applied Thermal Engineering, vol. 30, no. 14, pp. 2034-2044, 2010.

[9] X. Zhang, Z. D. Wang, Q. Liu et al., "Numerical Investigation of Influences of Coolant Types on Flow Distribution and Pressure Drop in Disc Type Transformer Windings," in International Conference on Condition Monitoring and Diagnosis (CMD), 2016, Xi'an, P.R. China, 2016, pp. 52-55.

[10] P. Picher, F. Torriano, M. Chaaban et al., "Optimization of Transformer Overload Using Advanced Thermal Modelling," in CIGRE Conference, Paris, France A2-305, 2010.

[11] X. Zhang, Z. D. Wang, and Q. Liu, "Interpretation of Hot Spot Factor for Transformers in OD Cooling Modes," IEEE Transactions on Power Delivery, vol. under review, 2017. 